Portland State University

PDXScholar

3-1-2018

\title{
Evaluation of Synthetic Dyes and Food Additives in Electronic Cigarette Liquids: Health and Policy Implications
}

Tetiana Korzun

Portland State University

Follow this and additional works at: https://pdxscholar.library.pdx.edu/honorstheses Let us know how access to this document benefits you.

\section{Recommended Citation}

Korzun, Tetiana, "Evaluation of Synthetic Dyes and Food Additives in Electronic Cigarette Liquids: Health and Policy Implications" (2018). University Honors Theses. Paper 499.

https://doi.org/10.15760/honors.502

This Thesis is brought to you for free and open access. It has been accepted for inclusion in University Honors Theses by an authorized administrator of PDXScholar. Please contact us if we can make this document more accessible: pdxscholar@pdx.edu. 
Evaluation of synthetic dyes and food additives in electronic cigarette liquids:

Health and policy implications

by

Tetiana Korzun

An undergraduate honors thesis submitted in partial fulfillment of the requirements for the degree of

Bachelor of Science

in

University Honors

and

Biology

Thesis Advisers

Professor Robert M. Strongin, PhD

Dr. R. Paul Jensen, PhD

Portland State University 


\section{TABLE OF CONTENTS}

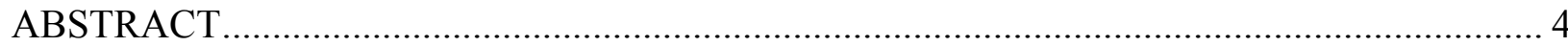

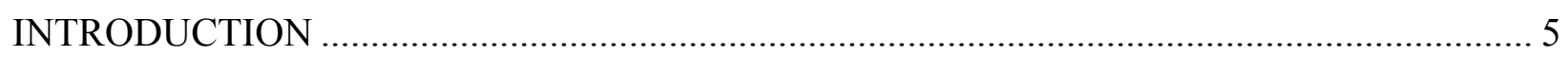

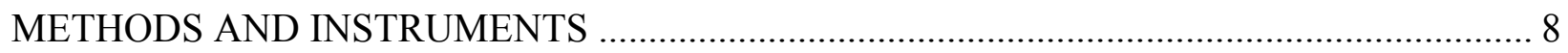

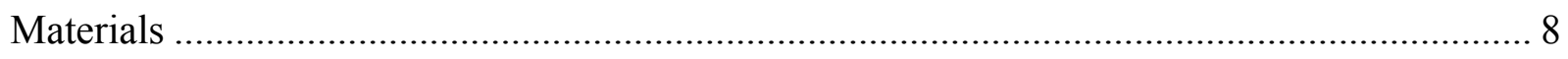

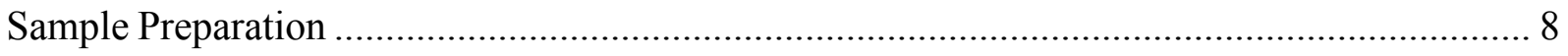

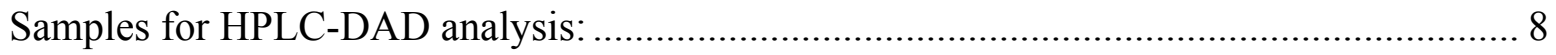

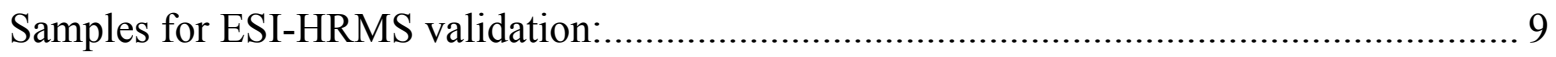

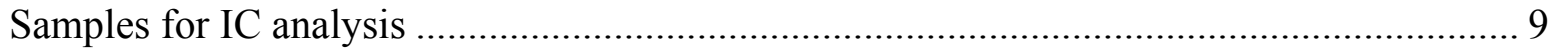

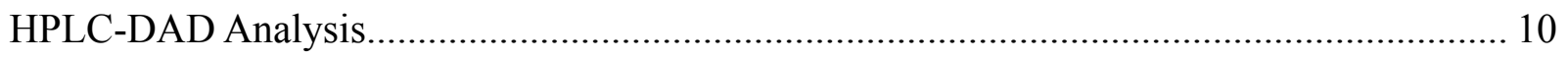

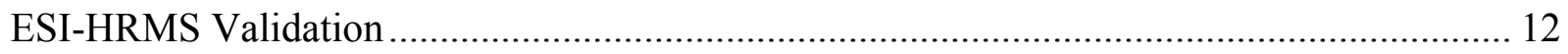

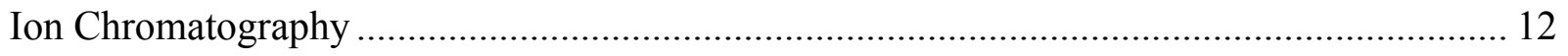

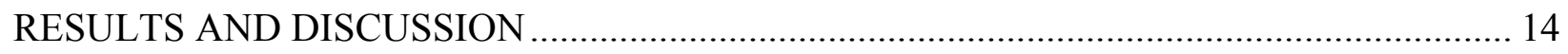

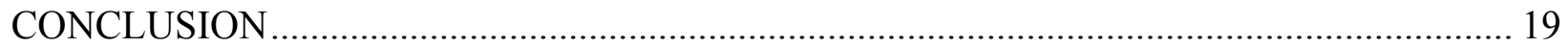

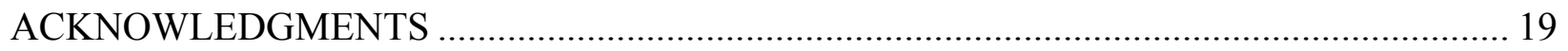

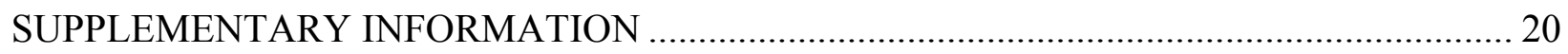

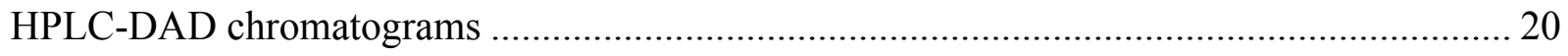

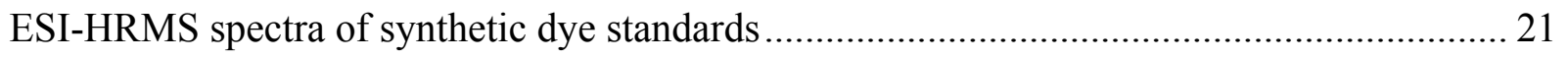

ESI-HRMS validation of synthetic dyes in e-liquid samples ............................................... 23

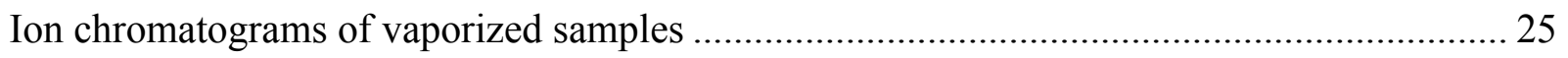

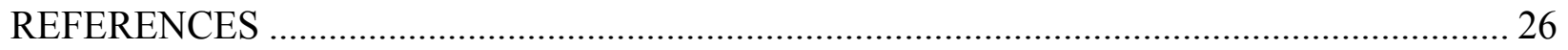




\section{INDEX OF TABLES}

Table 1. Quantitative features of the HPLC-DAD method for the selected dye standards......... 11

Table 2. Quantitative features of the ESI-HRMS method for the selected dye standards.......... 12

Table 3. Seven synthetic dyes used in foods. Chemical classes and ingestion ADIs. ................ 14

Table 4. Identification and quantification of unknown dyes in the samples of commercially

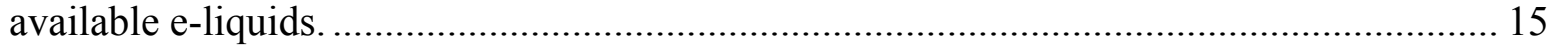

Table 5. ESI-HRMS validation of unknown dyes in commercially available e-liquids............. 16

Table 6. Synthetic dye concentrations in selected foodstuffs. ............................................... 16

Table 7. Sulfate and chloride concentration in vaporized e-liquid samples............................ 18

\section{TABLE OF FIGURES}

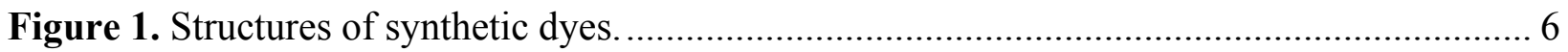

Figure 2. Representative chromatograms of synthetic dye standards .................................... 11

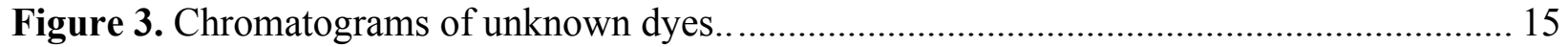

\section{SUPPLEMENTARY INFORMATION}

Figure S1. Additional chromatograms of dyes standards ............................................... 20

Figure S2. ESI-HRMS spectrum of Allura Red AC Standard........................................... 21

Figure S3. ESI-HRMS spectrum of Erythrosine Standard. ................................................. 21

Figure S4. ESI-HRMS spectrum of Fast Green FCF Standard ............................................ 21

Figure S5. ESI-HRMS spectrum of Tartrazine Standard .................................................... 22

Figure S6. ESI-HRMS spectrum of Sunset Yellow FCF Standard........................................ 22

Figure S7. ESI-HRMS spectrum of Brilliant Blue FCF Standard .......................................... 22

Figure S8. ESI-HRMS spectrum of Allura Red AC in Red E-liquid ..................................... 23

Figure S9. ESI-HRMS spectrum of Tartrazine in Green E-liquid ....................................... 23

Figure S10. ESI-HRMS spectrum of Brilliant Blue FCF Dye in Green E-liquid...................... 23

Figure S11. ESI-HRMS spectrum of Brilliant Blue FCF in Blue E-liquid.............................. 24

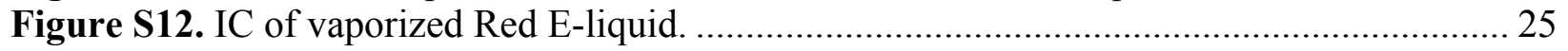

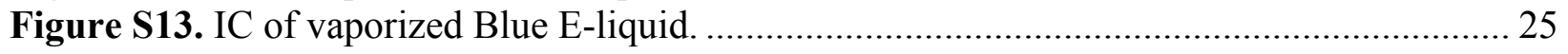

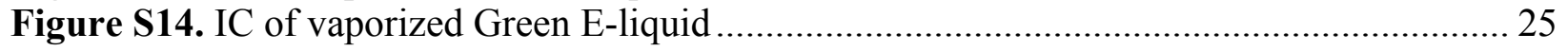


To beloved chemists and the physicist

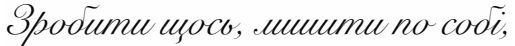

$$
\begin{aligned}
& \text { ами, нігого, - пройдемо, ак тіні, }
\end{aligned}
$$

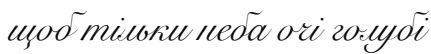

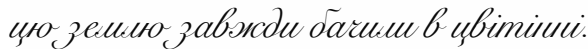

$$
\begin{aligned}
& \text { Ulоо уіл міси не Вимери, ак тур, }
\end{aligned}
$$

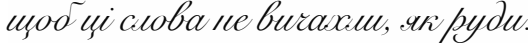

$$
\begin{aligned}
& \text { Humma ide ibce óez nopermyp, } \\
& \text { isn напишеш, man ysice is öyde. } \\
& \text { liна Troсmенко }
\end{aligned}
$$




\begin{abstract}
Prior studies of e-liquid thermal degradants do not reflect many of the potential health hazards related to e-cigarettes. Although current studies have focused on solvents and flavoring additives in e-cigarette formulations, there have been no prior reports on the identity and levels of synthetic dye additives. Therefore, the purpose of this study was to identify and quantify these compounds to enhance understanding of the risks associated with the inhalation of colored eliquids. Furthermore, e-liquids were subjected to thermal degradation under normal vaping conditions to quantify the sulfur oxides $\left(\mathrm{SO}_{\mathrm{x}}\right)$ content indicating dye decomposition. The dyes were analyzed by a combination of high-performance liquid chromatography and high resolution mass spectroscopy. The thermal decomposition of dyes in vaporized e-liquid samples was studied by ion chromatography. The findings of this investigation revealed that e-liquid manufacturers added synthetic dyes in concentrations comparable to those used in the food industry. In addition, $\mathrm{SO}_{\mathrm{x}}$ were present in the aerosolized e-liquids suggesting that dyes undergo thermal degradation. The aerosol samples contained a substantial amount of free chloride, which could be associated with a breakdown of the sucralose molecules, whose presence in the eliquids was confirmed by nuclear magnetic resonance.
\end{abstract}




\section{INTRODUCTION}

Electronic cigarettes (e-cigarettes) may pose dangers to consumers, due to a lack of formal oversight regarding their regulation and manufacturing. In addition, the long-term effects of vaping on human health remain to be unknown. However, e-cigarettes are frequently lauded to be a healthier alternative to tobacco products. For decades, tobacco manufacturers have faced heavy advertising restrictions, in large part to avoid encouraging tobacco use among children. It is known that advertising has a positive correlation with youth cigarette smoking. ${ }^{1}$ The bright packaging designs of e-liquids, as well as their pleasant aromas (and potentially colors), are known to be enticing to young people. ${ }^{2,3}$ These attractive products, readily available on the largely unregulated market, ${ }^{4}$ are manufactured and advertised in a relaxed regulatory environment. As a result, in recent years, e-liquid poisoning amongst children has increased by $1500 \%{ }^{5}$ This includes child fatalities associated with e-liquid nicotine ingestion overdoses. ${ }^{6}$ If appealing color and flavoring additives in e-liquid formulations remain, there are substantive health risks to our nation's youth.

The current lack of regulations allows manufacturers to add new ingredients that have no associated inhalation toxicological data. The yields of toxic aldehydes and related compounds that are produced via the thermally-induced degradation of propylene glycol and glycerol (the eliquid solvents) are enhanced by the decomposition of additives that are often not listed as eliquid ingredients and are considered to be the manufacturing secrets. ${ }^{7,8}$

Food additives influence the consumers' perception of food flavor and flavor identity. ${ }^{9}$ Such additives are classified as generally recognized as safe (GRAS) for ingestion. ${ }^{10}$ However, their inhalation toxicity is unknown. Two categories of color additives used in food and drugs in the US include those certified and those exempt from certification. They are categorized based 
on the US Food and Drug Administration (FDA) testing requirements. ${ }^{11,12}$ Certified food dyes are synthetic compounds that are widely used because of their uniform color and shelf-life stability, as well as their ability to encompass a full spectrum of colors when mixed, while not impacting or altering food taste. ${ }^{13}$ The synthetic dyes shown in Figure $\mathbf{1}$ are certified by the FDA for use in food, as well as in drugs and cosmetics (FD\&C). Other FD\&C colorants, not shown here, are dyes that are certified for usage only in specific foods (i.e. Orange B and Citrus Red No. 2 are used to color the surfaces of sausages and oranges, respectively). ${ }^{14}$

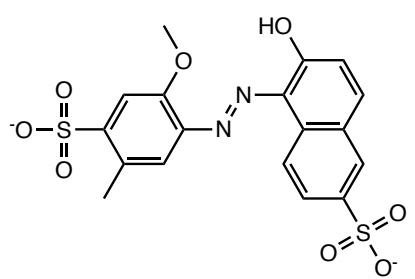

Allura Red AC (FD\&C Red No. 40)
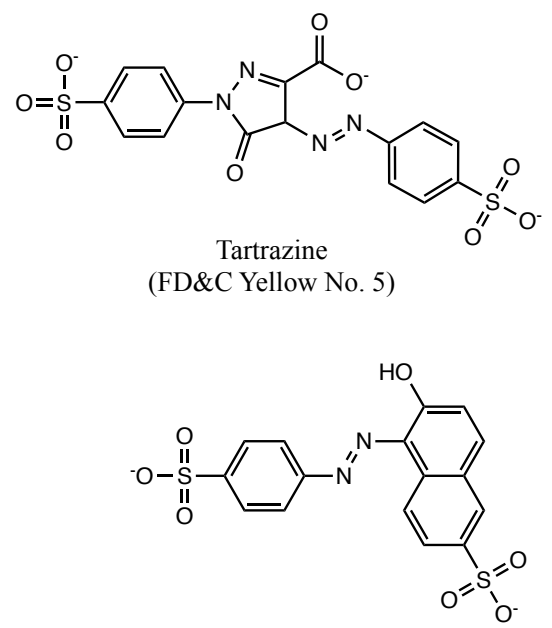

Sunset Yellow FCF (FD\&C Yellow No. 6)

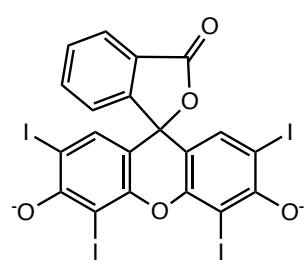

Erythrosine (FD\&C Red 3)
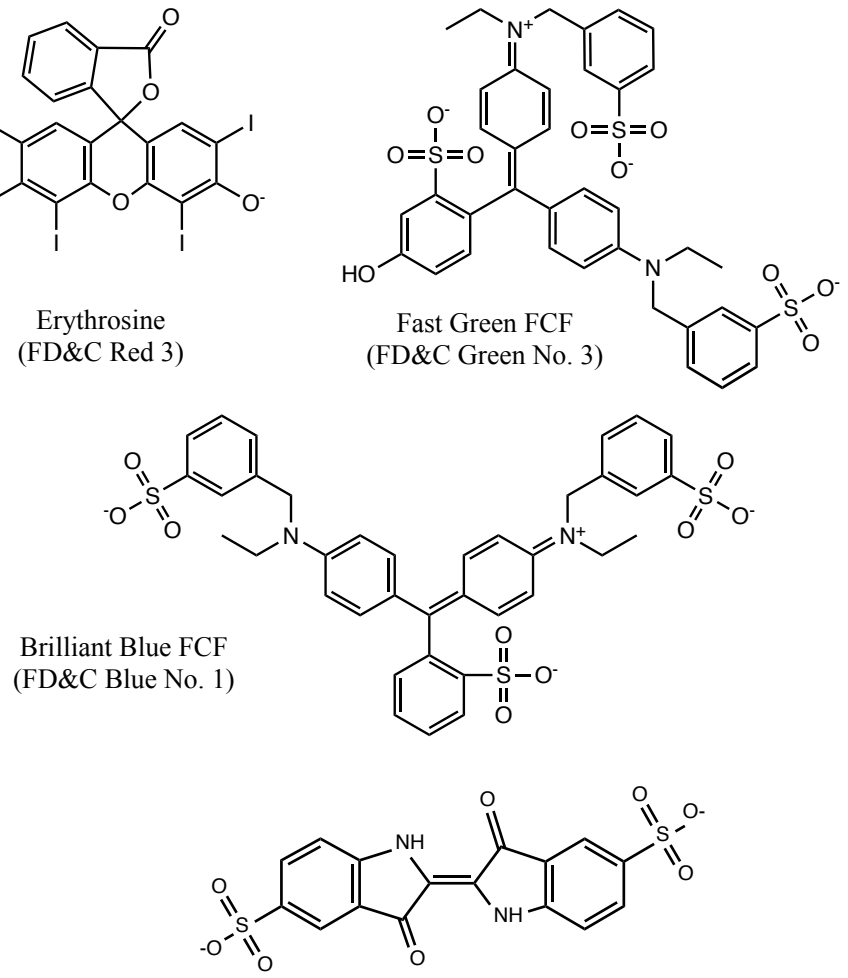

(FD\&C Blue No. 2)

Figure 1. Structures of synthetic dyes.

Although disclosing the identity of synthetic dyes is mandatory on the labels of foodstuffs, ${ }^{12}$ this information is absent on the vast majority of e-liquid labels. Additionally, acceptable daily intake (ADI) values for dye inhalation are not provided by the FDA, as synthetic dyes had not been used or intended for inhalation previously. 
Herein, the purpose of this study was to identify and quantify the specific coloring compounds in commercially available e-liquids in order to enhance our understanding of their potential risks associated with inhalation and to help raise awareness about the inhalation of substances originally intended for ingestion. 


\section{METHODS AND INSTRUMENTS}

\section{Materials}

Three e-liquids were ordered from the manufacturer's online shop. All HPLC-grade solvents (acetonitrile, methanol and water) were from Fisher Scientific (Fisher Scientific Co., Chicago, IL, USA). Dibasic ammonium phosphate (ACS reagent, $\geq 98 \%$ ) and potassium hydroxide (ACS reagent grade, $>85 \%$, pallets) were used for HPLC buffer preparation and were obtained from Sigma-Aldrich (Sigma Aldrich, St. Louis, MO, USA). Perchloric acid (70 \% aqueous solution; Acros Organics) and hydrogen peroxide (30\% aqueous solution; Sigma Aldrich, St. Louis, MO, USA) were used for absorption solution preparation in ion chromatography experiments. Analytical standards of Allura Red AC (FD\&C Red 40), Sunset Yellow FCF (FD\&C Yellow 6), Tartrazine (FD\&C Yellow 5), Brilliant Blue FCF (FD\&C Blue 1), Fast Green FCF (FD\&C Green 3), Erythrosine (FD\&C Red 3) and Indigo Carmine (FD\&C Blue 2) were obtained from Sigma Aldrich (Sigma Aldrich, St. Louis, MO, USA). Water for sample preparation was purified using Thermo Scientific Barnstead GenPure xCAD Plus UV-TOC Water Purification System (Thermo Scientific, Waltham, MA, USA).

\section{Sample Preparation}

Samples for HPLC-DAD analysis: E-liquids were diluted with water (1:5 dilution) and sonicated for 20 minutes. The standard solutions of Allura Red AC, Fast Green FCF, Sunset Yellow FCF, Erythrosine, Tartrazine, Brilliant Blue FCF were prepared in water by dissolving the solid powders to obtain a stock concentration of $1 \mathrm{mg} / \mathrm{mL}$. Four to eight calibration concentrations were prepared from stock solutions and used for calibration curves construction with curves forced through the origin. The concentration ranges for standard 
solutions were 20-80 $\mu \mathrm{g} / \mathrm{mL}$ for Allura Red AC, Fast Green FCF, Sunset Yellow FCF and Erythrosine, and 2.5-80 $\mu \mathrm{g} / \mathrm{mL}$ for Tartrazine and Brilliant Blue FCF. Each unknown and standard solution were filtered (PVDF, $0.22 \mu \mathrm{m}$ pore size) and subjected to HPLC-DAD analysis.

Samples for ESI-HRMS validation: dye samples from three e-liquids were concentrated using SPE cartridges (Oasis HLB cartridges, Waters, Milford, MA, USA), connected to the vacuum manifold system (Waters, Milford, MA, USA) and the vacuum inlet. Cartridges were conditioned using $3 \mathrm{ml}$ of methanol and $5 \mathrm{ml}$ of deionized water at a flow rate of about 1 drop per minute. E-liquid samples diluted in water were transferred to the SPE cartridges. The loaded cartridges were rinsed with $5 \mathrm{ml}$ of water allowing e-liquid solvent separation at a flow rate of about 2 drops per minute. The cartridges were eluted with two 3-mL methanol rinses at the same flow rate. The eluent sample volumes containing dyes were reduced by rotary evaporation (R-210 Rotavap, Buchi, New Castle, De, USA). The residues were reconstituted in $1 \mathrm{ml}$ of methanol. SPE of red and blue e-liquids yielded two samples containing red and blue dyes, respectively; SPE of the green e-liquid yielded a combination of two samples of yellow and blue dyes. The standard solutions of Allura Red AC, Fast Green FCF, Sunset Yellow FCF, Erythrosine, Tartrazine, Brilliant Blue FCF dyes were prepared in water to give a final concentration of $20 \mathrm{Mm}$. Note, Indigotine was not used for ESI-HRMS analysis.

Samples for IC analysis: the vapor was generated using the electronic cigarette consisted of Tesla Invader III battery unit (Teslacigs, Shenzhen, China) with two 18650 HG2 batteries (3.7 V, 3000 mAh) (LG Chem, Holland, MI) and KangerTech SubTank Mini atomizer with horizontal kenthal coil (1.2 $\Omega$ resistance) (KangerTech, Shenzhen, China). The ecigarette was operated at $17 \mathrm{~W}$. The aerosol was drawn into a $-78^{\circ} \mathrm{C}$ cold trap (dry ice/acetone) 
followed by the impinger containing acidified hydrogen peroxide absorption solution. The setup was connected to the SCSM-STEP single cigarette-smoking machine, simulating inhalation (CH Technologies, Westwood, NJ). Aerosol was produced using CORESTA vaping mode (3-

s puff with 1-s power button activation prior vaping, 30 -s puff intervals, 55 -mL puff volume). ${ }^{15}$ The sample from the cold trap was combined with the impinger solution. The samples were immediately subjected to analysis by ion chromatography. Triplicate experiments were performed using each e-liquid; each replicate represents the session of 40 puffs ( 20 puffs -20 minutes cooling - 20 puffs).

\section{HPLC-DAD Analysis}

The samples of commercially available e-liquids were analyzed using adapted HPLCDAD method. ${ }^{16}$ The HPLC-DAD set-up included 1525 Binary HPLC pump, 2996 Photodiode Array Detector and column heater (Waters, Milford, MA). The chromatographic separation was perfumed using Acclaim PA2 column with $3 \mu \mathrm{m}$ particle size, $3 \times 75 \mathrm{~mm}$ dimensions and injection volume of $5 \mu \mathrm{L}$ (Thermo Scientific, Waltham, MA). The DAD detector was set to 210-650 nm spectral range. The column was kept at $30^{\circ} \mathrm{C}$. The mobile phase consisted of

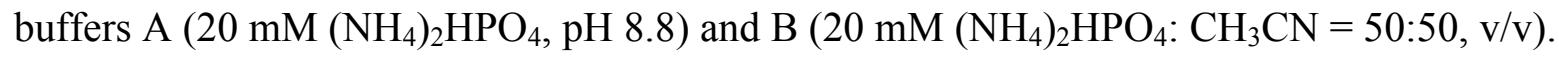
The analysis of standard solutions was performed using the gradient of $12 \% \mathrm{~B}$ from 0.00 to $3 \mathrm{~min}$, ramping to $100 \%$ from 3.00 to $3.50 \mathrm{~min}$ with hold for $1.0 \mathrm{~min}$, and return to $12 \% \mathrm{~B}$ in $0.1 \mathrm{~min}$ (flow rate of $0.71 \mathrm{~mL} / \mathrm{min}$ ). The e-liquid samples followed the same gradient program and flow, except that the $100 \%$ B hold was extended to $29.50 \mathrm{~min}$ and returned to $12 \%$ in $1 \mathrm{~min}$. 
Table 1. Quantitative features of the HPLC-DAD method for the selected dye standards

\begin{tabular}{cccccc}
\hline $\begin{array}{c}\text { Dye } \\
\text { Standard }\end{array}$ & $\begin{array}{c}\text { Absorption Maxima } \\
(\mathrm{nm})\end{array}$ & $\begin{array}{c}\text { Regression } \\
(\%)\end{array}$ & $\begin{array}{c}\text { LOD } \\
(\mu \mathrm{g} / \mathrm{mL})\end{array}$ & $\begin{array}{c}\text { LOQ } \\
(\mu \mathrm{g} / \mathrm{mL})\end{array}$ & $\begin{array}{c}\text { RSD } \\
(\%)\end{array}$ \\
\hline Allura Red AC & 506 & 99.998 & 0.27 & 0.88 & 1.37 \\
Fast Green FCF & 619 & 99.988 & 0.97 & 3.23 & 2.39 \\
Sunset Yellow FCF & 485 & 99.972 & 1.60 & 5.35 & 0.36 \\
Erythrosine & 530 & 99.972 & 1.57 & 5.23 & 2.45 \\
Tartrazine & 426 & 99.991 & 0.57 & 1.91 & 0.81 \\
Brilliant Blue FCF & 630 & 99.973 & 0.10 & 0.34 & 1.49 \\
\hline
\end{tabular}

Experiments and the construction of calibration curves were performed in triplicates.

Quantitative features of the HPLC-DAD method and chromatograms of the dye standards are presented in Table 1 and Figure 2 (additional chromatograms: Supplementary information). Empower 2 Chromatography Data Software was used for data collection and processing.
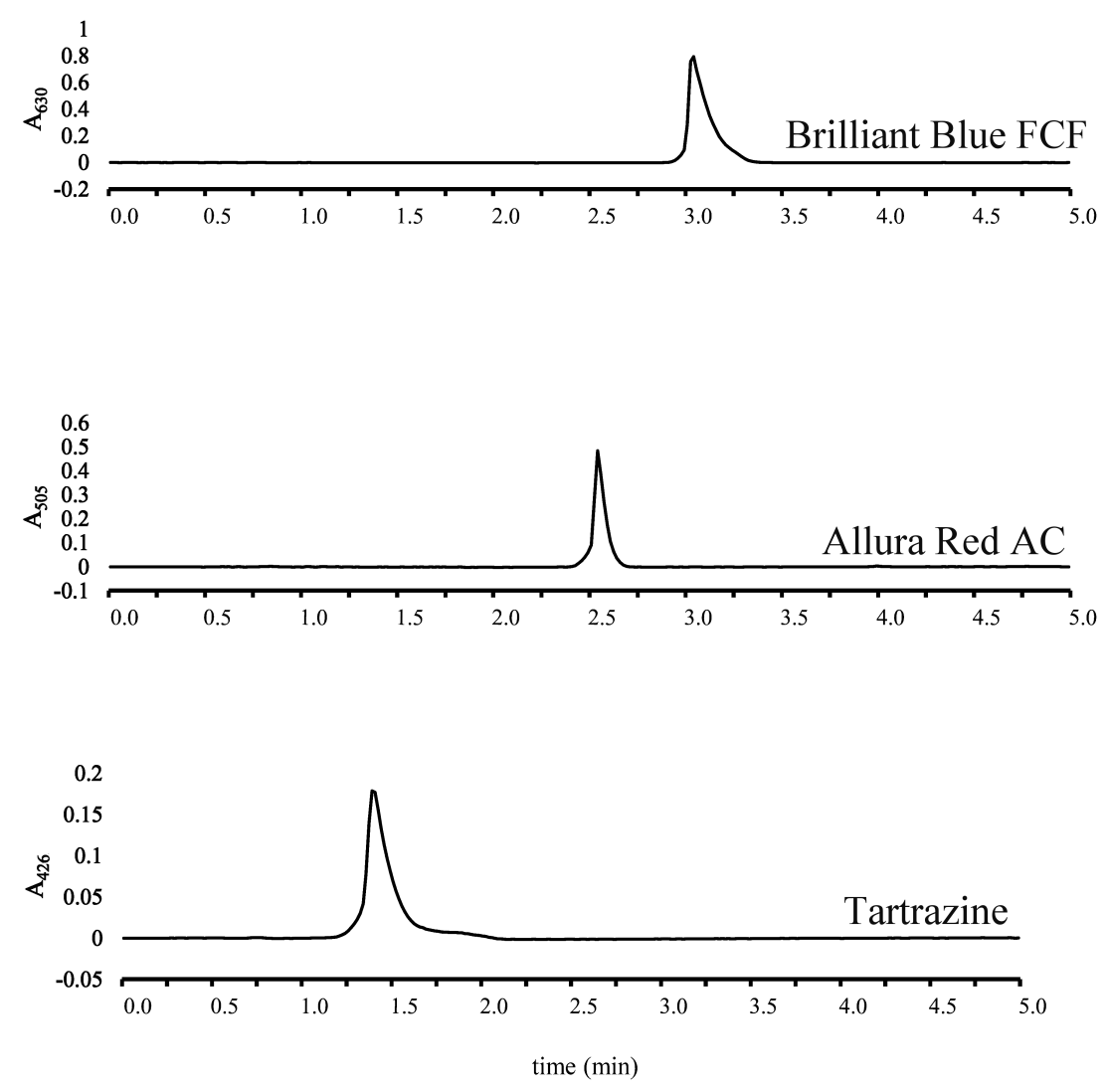

Figure 2. Representative chromatograms of synthetic dye standards. Standards at $40 \mu \mathrm{g} / \mathrm{mL}$ concentrations. 


\section{ESI-HRMS Validation}

Validation of identified analytes was performed using a high-resolution $(30,000$ resolution power) Thermo LTQ-Orbitrap Discovery hybrid mass spectrometry instrument equipped with Ion Max source with an electrospray ionization probe (Thermo Fisher Scientific, San Jose, CA, USA). The ionization interface was operated in the negative mode using the following settings: source voltage, $4 \mathrm{kV}$; sheath and aux gas flow rates, 50 and 5 units, respectively; tube lens voltage, $90 \mathrm{~V}$; capillary voltage, $49 \mathrm{~V}$; and capillary temperature, $300{ }^{\circ} \mathrm{C}$. The Orbitrap mass analyzer was externally calibrated prior to analysis. ESI-HRMS spectra of standards (molecular ions: Allura Red AC $\left[\mathrm{M}^{2-}\right.$, Brilliant Blue FCF $[\mathrm{M}]^{2-}$, Tartrazine $[\mathrm{M}]^{3-}$, Sunset Yellow FCF $[\mathrm{M}]^{2-}$, Erythrosine $[\mathrm{M}]^{2-}$ and Fast Green FCF $[\mathrm{M}]^{2-}$ ) revealed the molecular ion masses with accuracy within \pm 7 ppm (Table 2 and Supplemental information).

Table 2. Quantitative features of the ESI-HRMS method for the selected dye standards.

\begin{tabular}{ccc}
\hline Standard & $\begin{array}{c}\text { Calculated Mass of Standards } \\
(\mathrm{m} / \mathrm{z})\end{array}$ & $\begin{array}{c}\text { Observed Mass of Standards } \\
(\mathrm{m} / \mathrm{z})\end{array}$ \\
\hline Allura Red AC & 225.00903 & 225.00924 \\
Brilliant Blue FCF & 373.07077 & 373.07067 \\
Tartrazine & 154.99315 & 154.99263 \\
Sunset Yellow FCF & 202.99592 & 202.99515 \\
Erythrosine & 834.64667 & 834.64394 \\
Fast Green FCF & 381.06823 & 381.06713 \\
\hline
\end{tabular}

\section{Ion Chromatography}

Anion analysis of the vaped samples was conducted using an Dionex ICS-5000 ion chromatography system (Dionex, Sunnyvale, CA), outfitted with a conductivity detector cell and electrolytically regenerated suppressor (AERS 500, 4mm; Dionex, Sunnyvale, CA). $25 \mu \mathrm{L}$ aliquots of the filtered $(0.2 \mu \mathrm{m}$ pore size $)$ samples were injected onto the system for each run. The separation was carried out on an IonPac-AS15 with an IonPac-AG15 guard columns 
(Dionex, Sunnyvale, CA) and a flow of $0.75 \mathrm{~mL} / \mathrm{min}$. Gradient elution was used to obtain separation of the organic and inorganic peaks. The eluent concentrations were set as follows: 3 $\mathrm{mM} \mathrm{KOH}$ for 36.5 minutes, $45 \mathrm{mM} \mathrm{KOH}$ for 16.5 minutes, and $3 \mathrm{mM} \mathrm{KOH}$ for 7 minutes. Calibration curves were created using seven calibration standards with concentrations of chloride and sulfate ranging from 2.50 to $40.0 \mathrm{mg} / \mathrm{L}$ and 0.125 to $2.00 \mathrm{mg} / \mathrm{L}$, respectively (Supplementary Information). Data acquisition and analysis was performed using Chromeleon workstation. Linear calibration curves (without forcing the intercept through zero) were created based on peak height. R-squared values for all calibration curves were greater than 0.99; LOD values for chloride and sulfate were 0.063 and $0.079 \mathrm{mg} / \mathrm{L}$, and LOQ values were $0.19 \mathrm{mg} / \mathrm{L}$ and $0.24 \mathrm{mg} / \mathrm{L}$, respectively. 


\section{RESULTS AND DISCUSSION}

Three e-liquids were randomly chosen to represent the primary additive colors (red, green and blue). The manufacturers were contacted but declined the requests for the identity of ingredients, including the synthetic dyes used in the formulations.

Three dyes, Allura Red AC, Brilliant Blue FCF and Tartrazine, were identified in the eliquid samples. According to their structures, Allura Red AC and Tartrazine are azo dyes, and Brilliant Blue FCF is a triarylmethane (Table 3). Although these artificial food colorants are generally regarded as safe (GRAS) for human consumption, batches of Allura Red AC, Sunset Yellow FCF and Tartrazine are known to contain the human carcinogen benzidene and other aromatic amines ${ }^{17-20}$, while Tartrazine is a known potent allergenic agent. ${ }^{21-24}$

Table 3. Seven synthetic dyes used in foods. Chemical classes and ingestion ADIs.

\begin{tabular}{ccccc}
\hline Synthetic Dye & Chemical Class & $\begin{array}{c}\text { European ADI } \\
(\mathrm{mg} / \mathrm{kg} / \text { day })\end{array}$ & $\begin{array}{c}\mathrm{ADI}^{25} \\
(\mathrm{mg} / \mathrm{p} / \mathrm{day})^{\mathrm{a}}\end{array}$ & $\begin{array}{c}\text { Per Capita } \\
\text { Exposure }^{25} \\
(\mathrm{mg} / \mathrm{p} / \mathrm{day})^{\mathrm{a}}\end{array}$ \\
\hline $\begin{array}{c}\text { Allura Red AC } \\
\text { (FD\&C Red No. 40) }\end{array}$ & Azo & $0-7(2016)^{26}$ & 420 & 17.91 \\
$\begin{array}{c}\text { Sunset Yellow FCF } \\
\text { (FD\&C Yellow No. 6) }\end{array}$ & Azo & $0-2.5(1982)^{13}$ & 225 & 10.74 \\
$\begin{array}{c}\text { Tartrazine } \\
\text { (FD\&C Yellow No. 5) }\end{array}$ & Azo & $0-10(2016)^{26}$ & 300 & 12.06 \\
$\begin{array}{c}\text { Brilliant Blue FCF } \\
\text { (FD\&C Blue No. 1) }\end{array}$ & Triarylmethane & $0-12.5(1969)^{13}$ & 720 & 1.72 \\
$\begin{array}{c}\text { Fast Green FCF } \\
\text { (FD\&C Green No. 3) } \\
\begin{array}{c}\text { Erythrosine } \\
\text { (FD\&C Red No. 3) }\end{array}\end{array}$ & Triarylmethane & $0-25(1986)^{13}$ & 150 & 0.038 \\
$\begin{array}{c}\text { Indigotine } \\
\text { (FD\&C Blue No. 2) }\end{array}$ & Xanthene & $0-0.1(1990)^{13}$ & 150 & 0.61 \\
\hline Per 60-kg person & Sulfonated Indigo & $0-5(1974)^{13}$ & 150 & 1.95 \\
\hline
\end{tabular}

The identification and quantification of the dyes in the samples was performed by highperformance liquid chromatography-diode array method (HPLC-DAD). The chromatograms of three e-liquid samples were compared to chromatograms of the standard solutions of Allura Red AC, Sunset Yellow FCF, Tartrazine, Brilliant Blue FCF, Fast Green FCF, Erythrosine and 
Indigotine (Figure 3). The green e-liquid contained two dyes, Brilliant Blue FCF and

Tartrazine, at concentrations and proportions consistent with those used in the food industry to afford neon green solutions. ${ }^{27}$ The blue and red e-liquids contained Brilliant Blue FCF and Allura Red AC food colorants, respectively (Table 4).

Table 4. Identification and quantification of unknown dyes in the samples of commercially available e-liquids.

\begin{tabular}{ccccc}
\hline Sample & $\begin{array}{c}\text { Identified } \\
\text { Dye }\end{array}$ & $\begin{array}{c}\text { Absorption Maxima } \\
(\mathrm{nm})\end{array}$ & $\begin{array}{c}\text { Retention time } \\
(\mathrm{min})\end{array}$ & $\begin{array}{c}\text { Concentration } \\
(\mu \mathrm{g} / \mathrm{g})^{\mathrm{a}}\end{array}$ \\
\hline Red & Allura Red AC & 505 & 2.38 & 66.71 \\
Blue & Brilliant Blue FCF & 630 & 3.01 & 51.42 \\
Green & Brilliant Blue FCF & 630 & 3.00 & 1.85 \\
Green & Tartrazine & 426 & 1.38 & 29.43 \\
\hline
\end{tabular}

${ }^{\mathrm{a}} \mu \mathrm{g}$ of synthetic dye per $\mathrm{g}$ of e-liquid

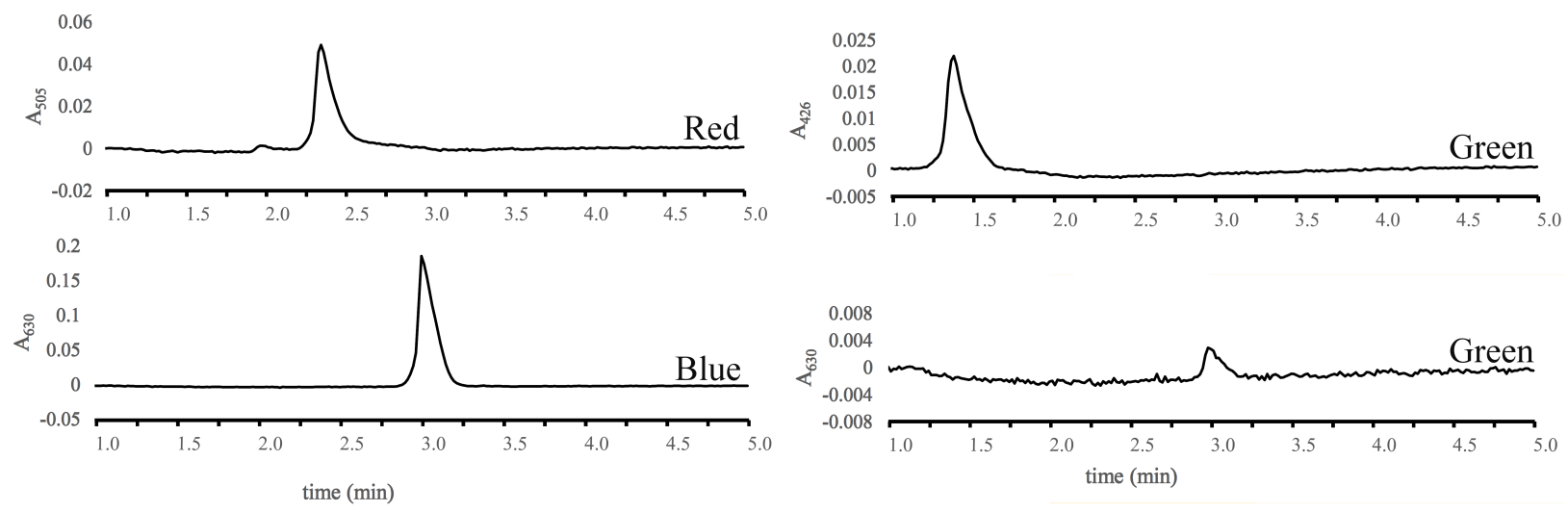

Figure 3. Chromatograms of unknown dyes.

Notice that the green sample is made of a combination of yellow and blue dyes. Detector wavelengths were set at $426 \mathrm{~nm}$ for Tartrazine, $505 \mathrm{~nm}$ for Allura Red AC and $630 \mathrm{~nm}$ for Brilliant Blue FCF.

Follow-up validation by high resolution electrospray ionization mass spectroscopy (ESIHRMS) confirmed the results obtained by HPLC-DAD method. Allura Red AC, Brilliant Blue FCF and Tartrazine were identified with mass accuracies within \pm 7 ppm (Table 5 and

\section{Supplementary information).}


Table 5. ESI-HRMS validation of unknown dyes in commercially available e-liquids.

\begin{tabular}{cccc}
\hline $\begin{array}{c}\text { E-liquid } \\
\text { Sample }\end{array}$ & Dye Identified & $\begin{array}{c}\text { Observed mass } \\
(\mathrm{m} / \mathrm{z})\end{array}$ & $\begin{array}{c}\text { Calculated mass } \\
(\mathrm{m} / \mathrm{z})\end{array}$ \\
\hline Red & Allura Red AC & 225.00829 & 225.00903 \\
Blue & Brilliant Blue FCF & 373.06815 & 373.07077 \\
Green & Brilliant Blue FCF & 373.07184 & 373.07077 \\
Green & Tartrazine & 154.99319 & 154.99315 \\
\hline
\end{tabular}

The overall data shows that manufacturers are using the three FDA certified dyes at concentrations similar to those used in the food industry (Table 6).

Table 6. Synthetic dye concentrations in selected foodstuffs.

\begin{tabular}{cccc}
\hline Foods & $\begin{array}{c}\text { Tartrazine } \\
(\mu \mathrm{g} / \mathrm{g})\end{array}$ & $\begin{array}{c}\text { Brilliant Blue FCF } \\
(\mu \mathrm{g} / \mathrm{g})\end{array}$ & $\begin{array}{c}\text { Allura Red AC } \\
(\mu \mathrm{g} / \mathrm{g})\end{array}$ \\
\hline Soft drinks $^{28}$ & $4.7-5.2$ & $1.0-1.2$ & 49.8 \\
Confectioneries $^{28}$ & $4.0-154.8$ & $1.0-6.3$ & ND \\
Water soluble foods $^{29}$ & 0.5 & $0.5-4.8$ & $18.1-27.8$ \\
Gummy candy $^{30}$ & $1.7-80.4$ & $0.7-9.6$ & $1.0-47.8$ \\
Jellies $^{30}$ & $2.2-20.2$ & $\mathrm{ND}$ & $\mathrm{ND}$ \\
Juices $^{31}$ & $0.06-121.82$ & $2.75-71.44$ & $5.77-7.15$ \\
Cookies $^{31}$ & $0.13-17.36$ & $0.90-0.99$ & ND \\
Fruit jam $^{32}$ & $\mathrm{ND}$ & $\mathrm{ND}$ & $17.9-33.4$ \\
Salted fish $^{32}$ & $136.0-292.5$ & $\mathrm{ND}$ & $\mathrm{ND}$ \\
Soft drinks $^{33}$ & 158 & $0.063-12.9$ & $0.107-0.14$ \\
Juice and jelly powder $^{34 \mathrm{a}}$ & $1.3-56.2$ & $2.9-6.4$ & $30.2-53.8$ \\
\hline
\end{tabular}

${ }^{a}$ Units for this study are $\mu \mathrm{g} / \mathrm{mL} ; \mathrm{ND}=$ not disclosed or not discovered in specified foods.

The justification for colorant addition to e-liquids in the same proportions relative to foodstuffs is likely to enable a vaper's identification of e-cigarette flavoring additives with corresponding foods. The color was shown to influence food sensory characteristics and acceptability of products due to possible learned associations of particular colors with foodstuffs. ${ }^{35,36}$ Other reasons for using artificial dyes in e-liquids could include the masking of unattractive natural colors of flavorings or other e-liquid constituents, or protecting e-liquids via the sunscreen effect ${ }^{13}$ to extend their shelf life. Although these reasons are valid for justifying 
dye addition to foods, the benefits of e-liquid color enhancement may be undermined due to the unknown health risks associated with the inhalation of dyes and their potential degradation byproducts.

Several conundrums arise regarding the lack of (i) certified dye labeling on e-cigarette packaging and (ii) acceptable daily intake (ADI) values for their inhalation. In agreement with the requirements of CFR 21, $§ 70.25$, certified synthetic dye identities are required on the labels of not only food products, but also on drugs and cosmetics. ${ }^{12}$ Although e-liquids are intended for human consumption, the identities of any dyes used are not required to be disclosed.

More importantly, there are no inhalation ADI values for these dyes, as inhalation is just emerging as an intended method of their consumption. The European ADI values for dye ingestion are defined by the Joint FAO/WHO Expert Committee on Food Additives (JECFA) and the European Food Safety Authority (EFSA). In the US, the ADI levels are regulated by the FDA and are listed in terms of dye intake in mg per 60-kg person (Table 3). To achieve an ADI upper limit of Brilliant Blue FCF (ADI: $720 \mathrm{mg} /$ person/day), a 60-kg person would have to inhale $14 \mathrm{~kg}$ of the blue e-liquid per day. In order to achieve an ADI value for Allura Red AC (ADI: 420 $\mathrm{mg} /$ person/day), one would have to inhale $6 \mathrm{~kg}$ of red e-liquid. For Tartrazine (ADI: 300 $\mathrm{mg} /$ person/day), the value would be $1 \mathrm{~kg}$ of green e-liquid. To reach average per-capita exposure levels listed by FDA (Table 3), a person would have to consume 34, 268 and $410 \mathrm{~g}$ of blue, red and green e-liquids, respectively (per-capita exposure levels for Brilliant Blue FCF, Allura Red AC and Tartrazine are 1.72, 17.91 and $12.06 \mathrm{mg} / 60-\mathrm{kg}$ person/day (Table 3).

In addition to the dilemma of inhaling these dyes, food colorants in e-liquids may produce toxic byproducts via thermal degradation. Some of the potential degradants can include dye precursors and aromatic amines that are considered to have carcinogenic potential. ${ }^{37}$ 
In vaped samples in the investigation herein, dye desulfonation was observed at a moderate operational power of the e-cigarette (Table 7 and Supplementary Information). The presence of sulfate $\left(\mathrm{SO}_{4}{ }^{2-}\right)$ ions in the collected aerosols indicates that sulfur dioxide $\left(\mathrm{SO}_{2}\right)$ or/and sulfur trioxide $\left(\mathrm{SO}_{3}\right)$ are released from the sulfonated dyes (and oxidized to $\mathrm{SO}_{4}{ }^{2-}$ according to the method described by Makkonen et al. for analysis). ${ }^{38}$ This suggests that the dyes start to degrade at temperatures as low as those needed to form e-liquid aerosols. ${ }^{7}$ The loss of sulfonate groups via thermal destruction in sulfonated dyes has been previously reported. ${ }^{39,40}$ Rehorek showed that the extent of desulfonation is a function of temperature due to the different positions of sulfonic group in the molecules (i.e., ortho, meta or para to the bonds adjoining the aryl rings), with parasulfonated compounds having the lowest optimal pyrolysis temperature. ${ }^{40}$ Accordingly, the green e-liquid showed the highest level of $\mathrm{SO}_{4}{ }^{2-}$ in the vaporized samples, as the yellow dye, tartrazine, has two para-sulfonyl groups.

In addition, the samples contained relatively high levels of free chloride $\left(\mathrm{Cl}^{-}\right)$(Table 7 and Supplementary Information). This could be derived from the breakdown of sucralose. The presence of sucralose in the e-liquids was confirmed by nuclear magnetic resonance. ${ }^{41} \mathrm{Cl}^{-}$or $\mathrm{SO}_{4}{ }^{2-}$ were not observed in the air samples, nor in the negative (absorption solution) or positive controls (e-liquid samples diluted in the absorption solution).

Table 7. Sulfate and chloride concentration in vaporized e-liquid samples.

\begin{tabular}{cccccccc}
\hline & & \multicolumn{3}{c}{$\begin{array}{c}\text { Mass concentration }\left[\mathrm{SO}_{4}{ }^{2-}\right] \\
(\mu \mathrm{g} / \mathrm{g})^{\mathrm{a}, \mathrm{b}}\end{array}$} & \multicolumn{3}{c}{$\begin{array}{c}\left.\text { Mass concentration } \mathrm{Cl}^{-}\right] \\
(\mu \mathrm{g} / \mathrm{g})^{\mathrm{a}}\end{array}$} \\
\hline & Replicate & 1 & 2 & 3 & 1 & 2 & 3 \\
\hline \multirow{2}{*}{ Red } & $>$ LOD & $>$ LOD & $>$ LOD & 23.38 & 56.34 & 36.48 \\
B. & Blue & $>$ LOD & 0.84 & 1.96 & 20.5 & 33.5 & 32.82 \\
& Green & $>$ LOD & 2.72 & 2.81 & 17.27 & 218.51 & 184.19 \\
\hline
\end{tabular}

${ }^{\mathrm{a}}$ analyte yield $(\mu \mathrm{g})$ per $\mathrm{g}$ of e-liquid consumed; ${ }^{\mathrm{b}} \mathrm{SO}_{4}{ }^{2-}$ was calculated back to $\mathrm{SO}_{2}$ 
While the in-depth investigation of sucralose decomposition was not an objective of the current study, finding chloride in the absorption solution suggested the fragmentation of sucralose molecules. The loss of hydrogen chloride $(\mathrm{HCl})$ from sucralose is a known initial step in its breakdown, and can ultimately lead to the release and/or formation of potentially toxic byproducts such as chloropropanols. ${ }^{42}$ Recent studies demonstrate that sucralose decomposition, including $\mathrm{HCl}$ release and the formation of chlorinated derivatives, occurs at relatively mild temperatures. ${ }^{43-44}$ The formation of chlorinated compounds from sucralose in the presence of glycerol (one of the two common e-liquid solvents) and metal oxides is well-precedented. ${ }^{45,46}$

\section{CONCLUSION}

The data presented herein suggests that the infusion of e-cigarette formulations with food additives, including synthetic dyes and sweeteners, creates potential health risks since their inhalation toxicity as well as the toxicity of their byproducts is largely unknown. We hope the results of this study will increase awareness and inform decisions about the regulation of ecigarettes, whether as inhalable foodstuffs, or as nicotine delivery matrices primarily intended for smoking cessation.

\section{ACKNOWLEDGMENTS}

I am deeply grateful to the Strongin Research Group for the immense support, practical guidance and the enormous contribution to this work. We thank the NIH and the FDA for their support via award R01ES025257. The content is solely the responsibility of the authors and does not necessarily represent the views of the NIH or the FDA. Support from the National Science Foundation (Grant number 0741993) for purchase of the LTQ-Orbitrap Discovery is gratefully acknowledged. 


\section{SUPPLEMENTARY INFORMATION}

\section{HPLC-DAD chromatograms}
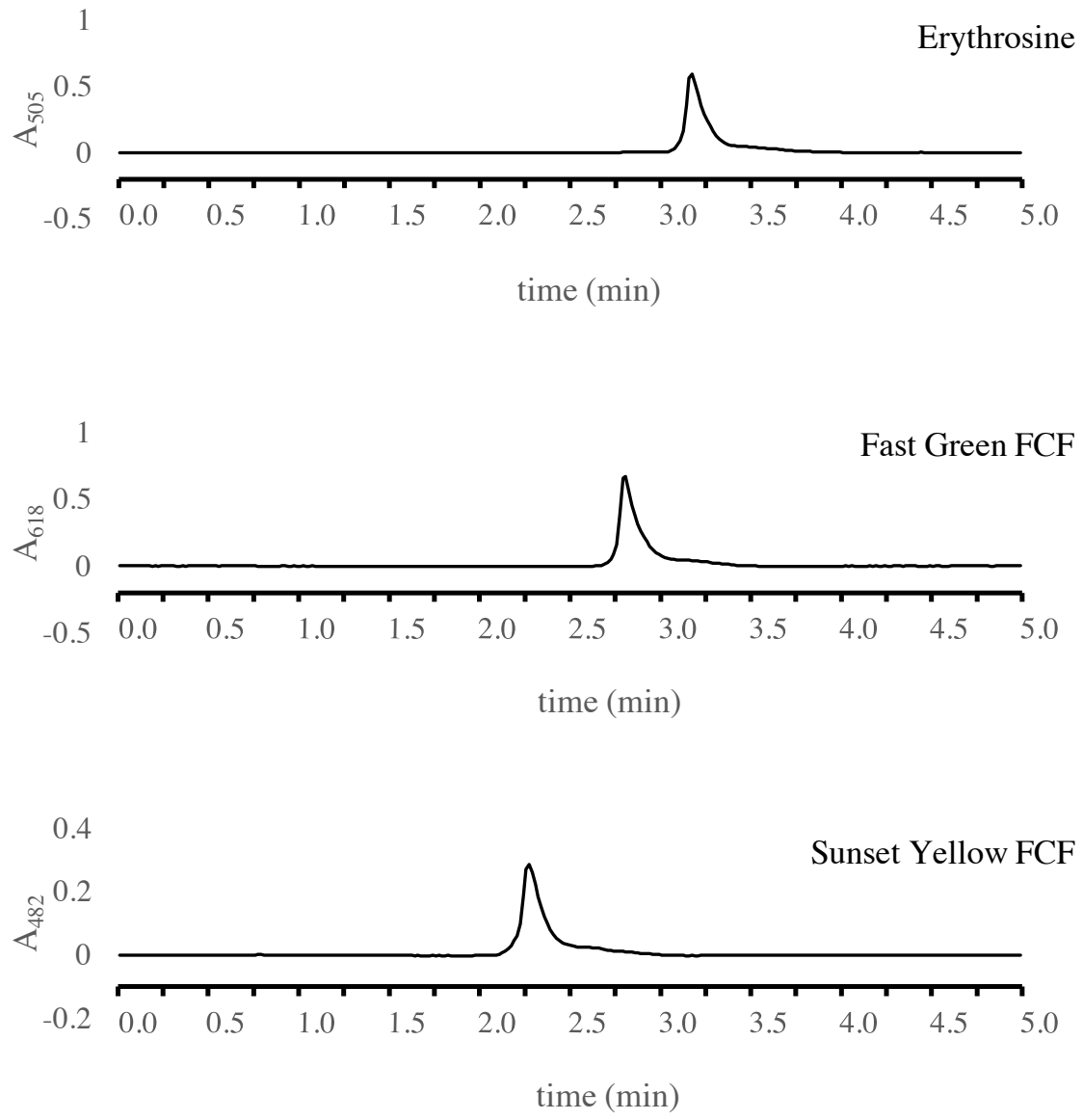

Figure S1. Additional chromatograms of dyes standards.

Standards at $40 \mu \mathrm{g} / \mathrm{mL}$ concentrations. 


\section{ESI-HRMS spectra of synthetic dye standards}

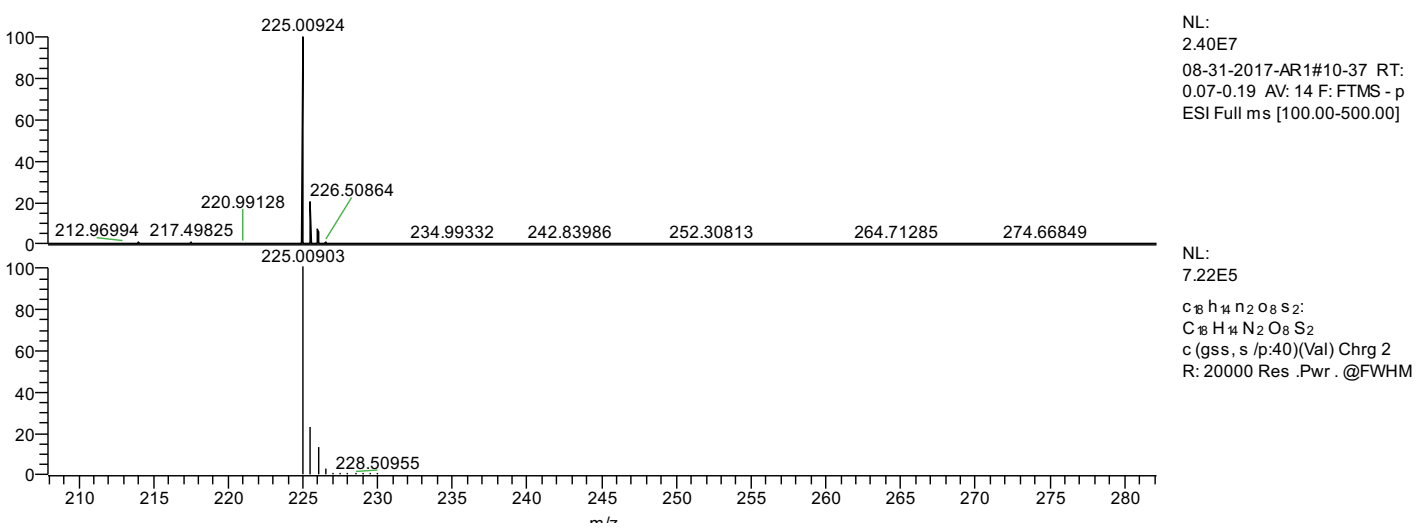

Figure S2. ESI-HRMS spectrum of Allura Red AC Standard.

$[\mathrm{M}]^{2-}$ ion. Theoretical mass: 225.00903 . Observed mass: 225.00924. $\Delta \mathrm{m} / z: 0.93 \mathrm{ppm}$

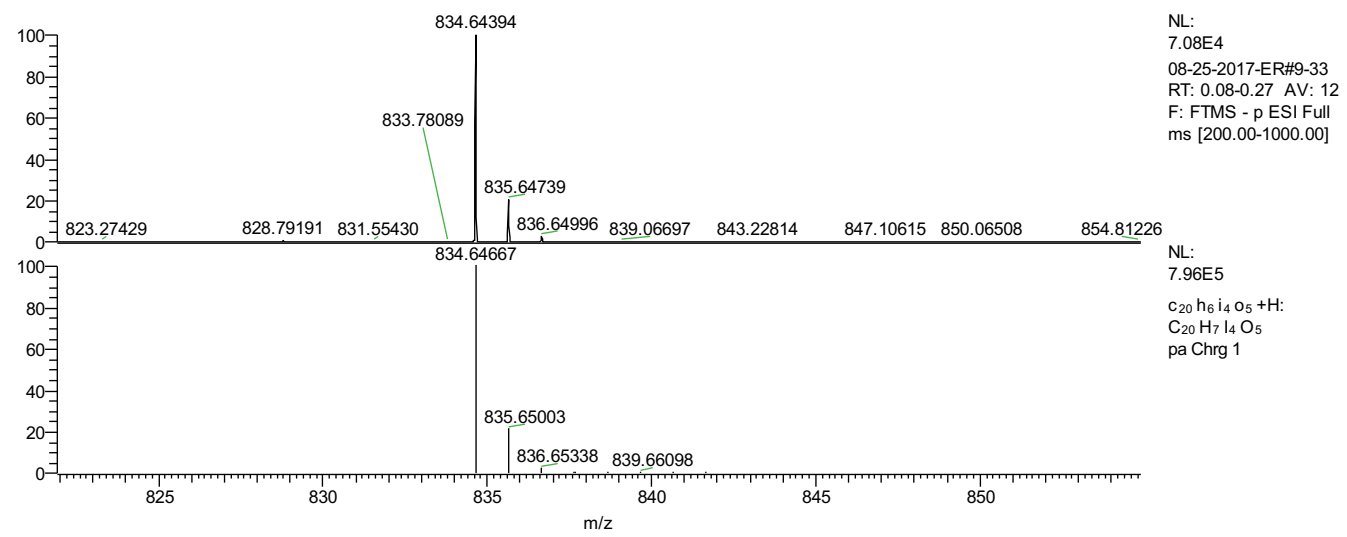

Figure S3. ESI-HRMS spectrum of Erythrosine Standard.

$[\mathrm{M}]^{2-}$ ion. Theoretical mass: 834.64667. Observed mass: 834.64394. $\Delta \mathrm{m} / \mathrm{z}: 3.27 \mathrm{ppm}$

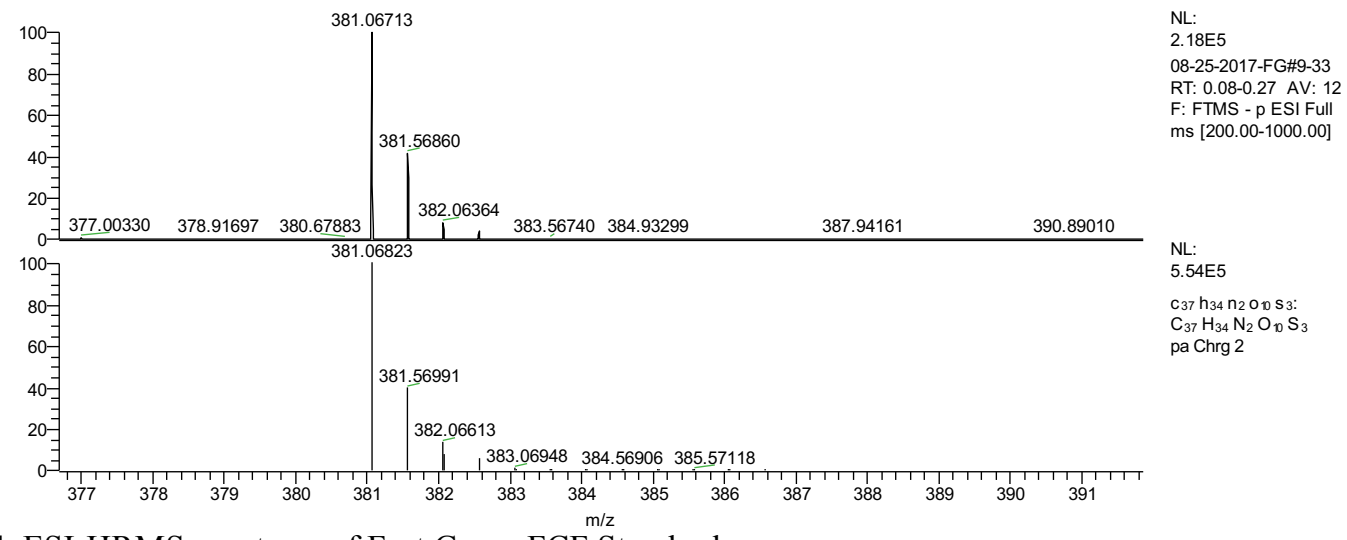

Figure S4. ESI-HRMS spectrum of Fast Green FCF Standard

$[\mathrm{M}]^{2-}$ ion. Theoretical mass: 381.06823 . Observed mass: $381.06713 . \Delta \mathrm{m} / \mathrm{z}: 2.89 \mathrm{ppm}$ 


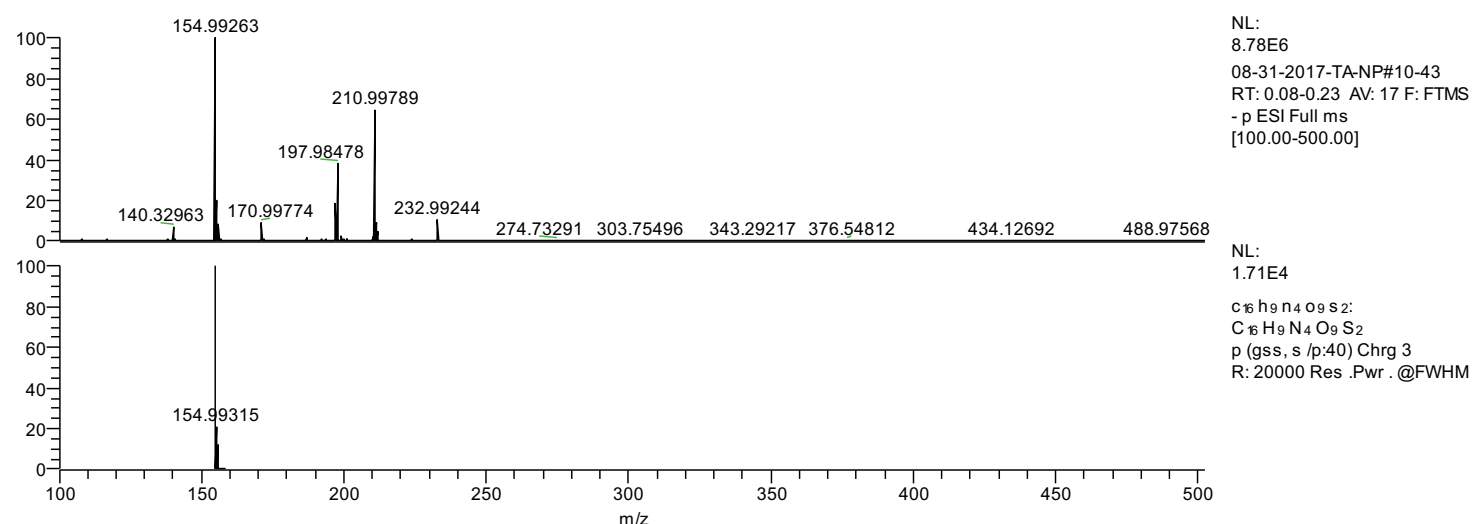

Figure S5. ESI-HRMS spectrum of Tartrazine Standard

$[\mathrm{M}]^{3-}$ ion. Theoretical mass: 154.99315 . Observed mass: $154.99263 . \Delta \mathrm{m} / \mathrm{z}: 3.35 \mathrm{ppm}$

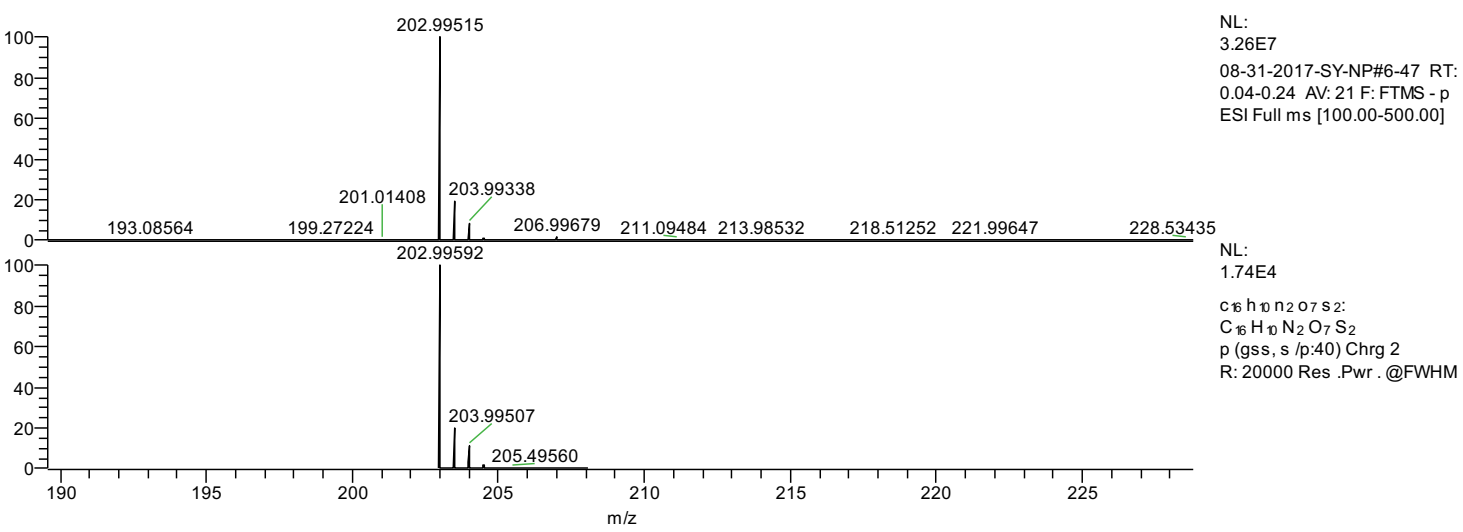

Figure S6. ESI-HRMS spectrum of Sunset Yellow FCF Standard.

$[\mathrm{M}]^{2-}$ ion. Theoretical mass: 202.99592. Observed mass: 202.99515. $\Delta \mathrm{m} / \mathrm{z}: 3.79 \mathrm{ppm}$

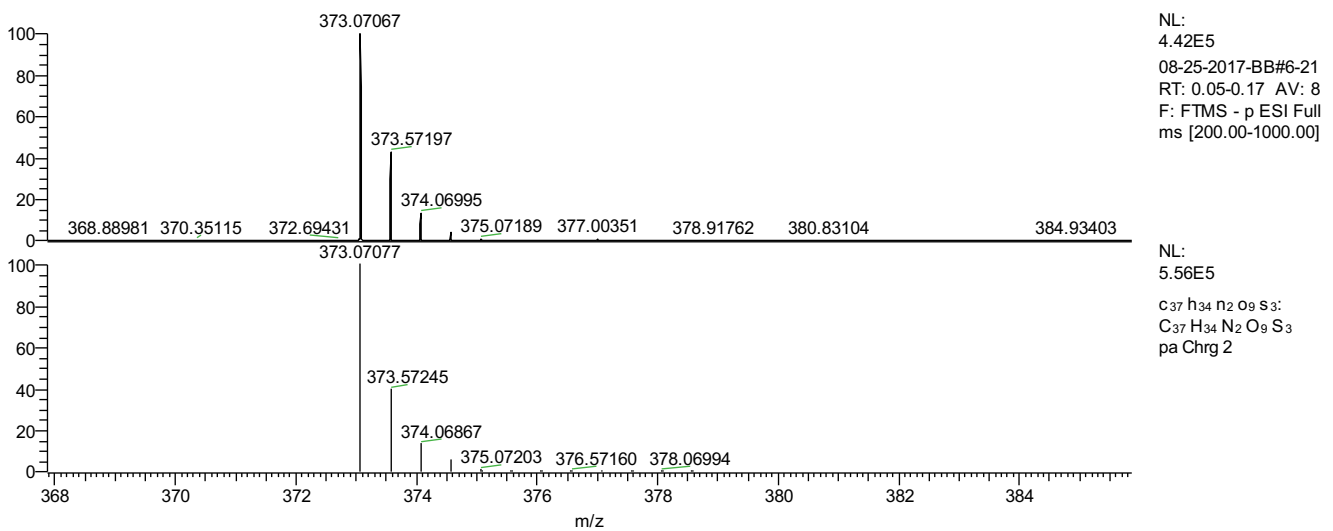

Figure S7. ESI-HRMS spectrum of Brilliant Blue FCF Standard.

$[\mathrm{M}]^{2-}$ ion. Theoretical mass: 373.07077 . Observed mass: $373.07067 . \Delta \mathrm{m} / \mathrm{z}: 0.27 \mathrm{ppm}$ 


\section{ESI-HRMS validation of synthetic dyes in e-liquid samples}

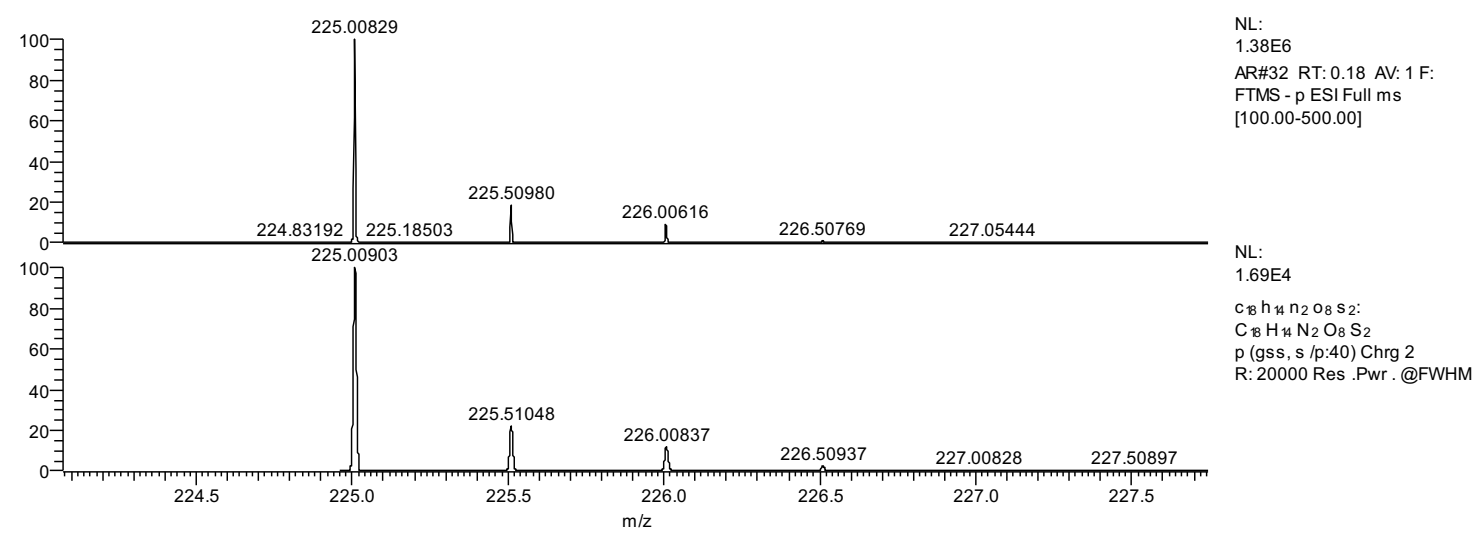

Figure S8. ESI-HRMS spectrum of Allura Red AC in Red E-liquid.

Theoretical mass: 225.00903. Observed mass: $225.00829 . \Delta \mathrm{m} / \mathrm{z}: 3.29 \mathrm{ppm}$

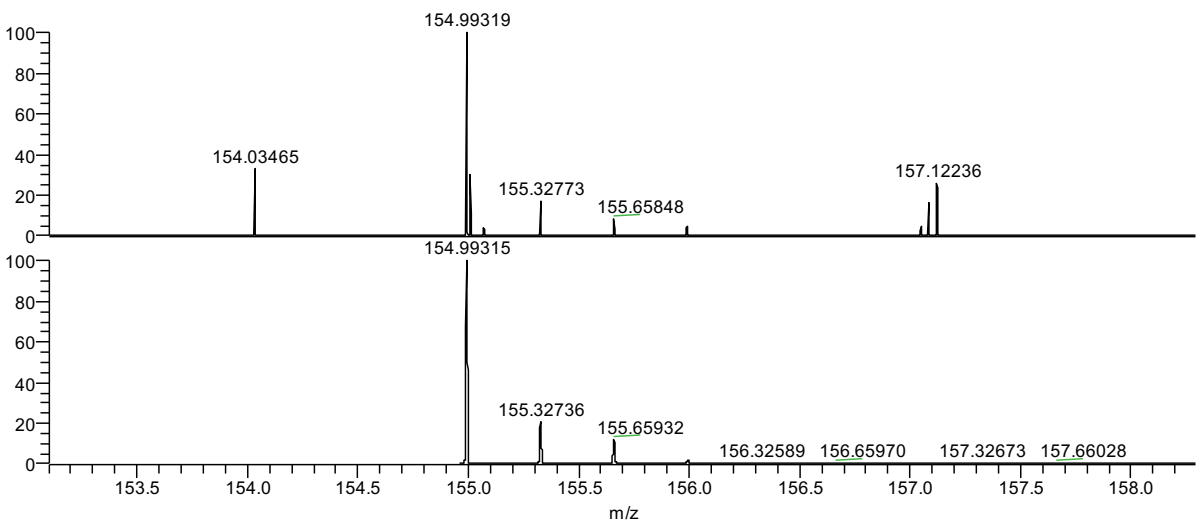

NL:

GREEN+TA\#178 RT: 0.99 AV: 1 F: FTMS - p ESI Full ms [100.00-500.00]

NL:

$1.71 \mathrm{E} 4$

C $16 h_{9} n_{4} 0_{9} S_{2}$ :

p (gss, s /p:40) Chrg 3

R: 20000 Res .Pwr.@FWHM

Figure S9. ESI-HRMS spectrum of Tartrazine in Green E-liquid.

Theoretical mass: 154.99315 . Observed mass: $154.99319 . \Delta \mathrm{m} / \mathrm{z}: 0.26 \mathrm{ppm}$

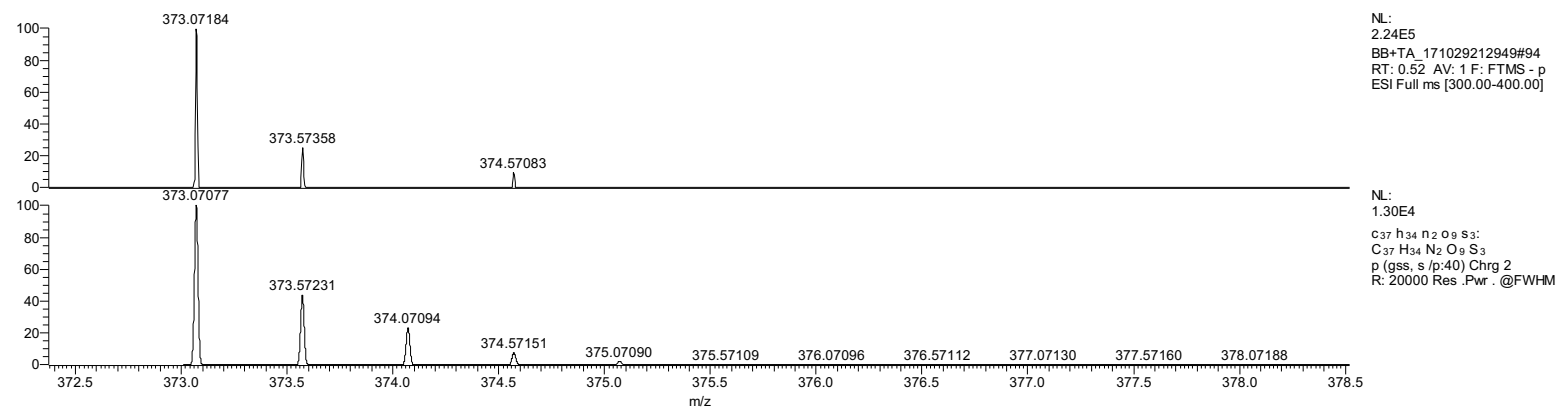

Figure S10. ESI-HRMS spectrum of Brilliant Blue FCF Dye in Green E-liquid.

Theoretical: 373.07077 . Observed: $373.07184 . \Delta \mathrm{m} / \mathrm{z}: 2.87 \mathrm{ppm}$ 


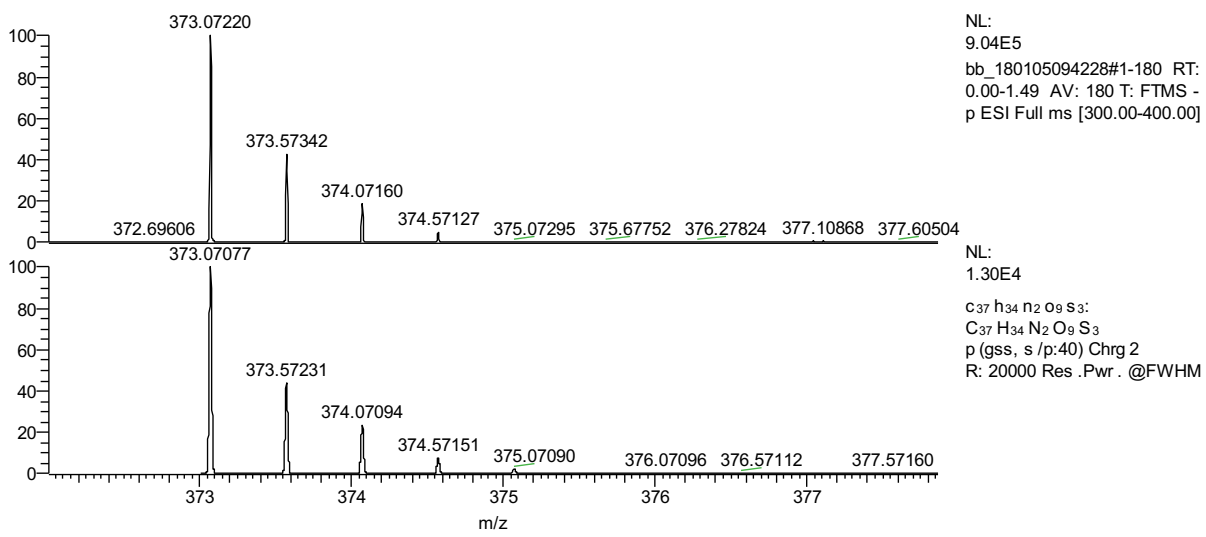

Figure S11. ESI-HRMS spectrum of Brilliant Blue FCF in Blue E-liquid. Theoretical mass: 373.07077 . Observed mass: $373.07220 . \Delta \mathrm{m} / \mathrm{z}: 3.83 \mathrm{ppm}$ 


\section{Ion chromatograms of vaporized samples}

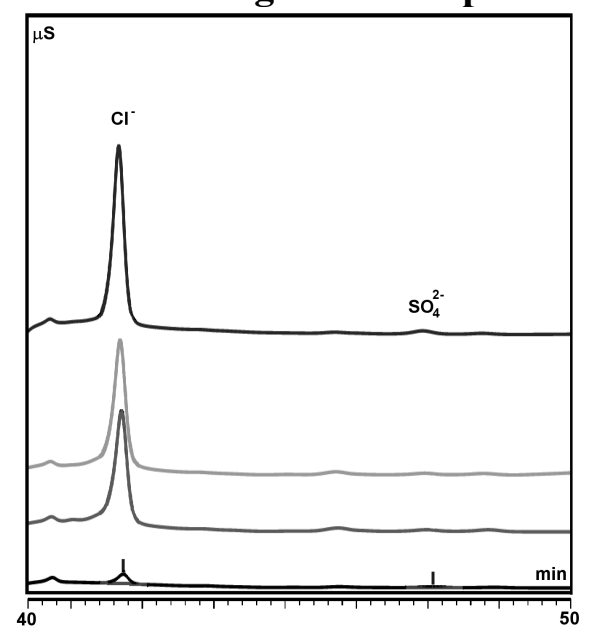

Figure S12. IC of vaporized Red E-liquid.

Bottom to top: replicates $1-3$ and the spiked sample.

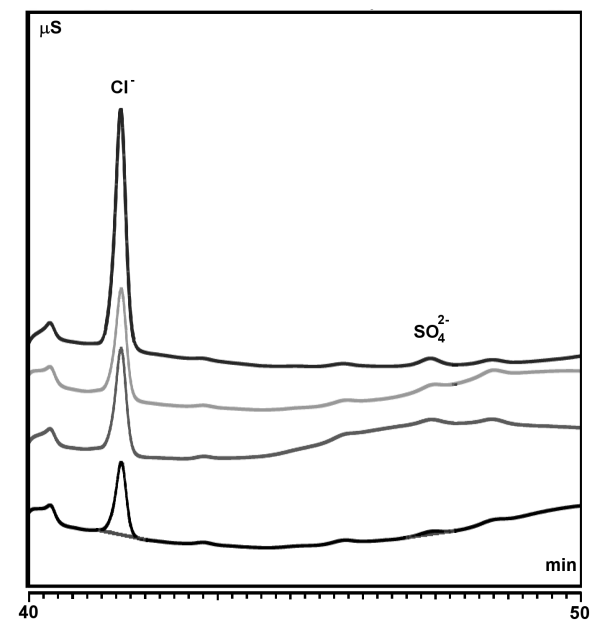

Figure S13. IC of vaporized Blue E-liquid.

Bottom to top: replicates $1-3$ and the spiked sample.

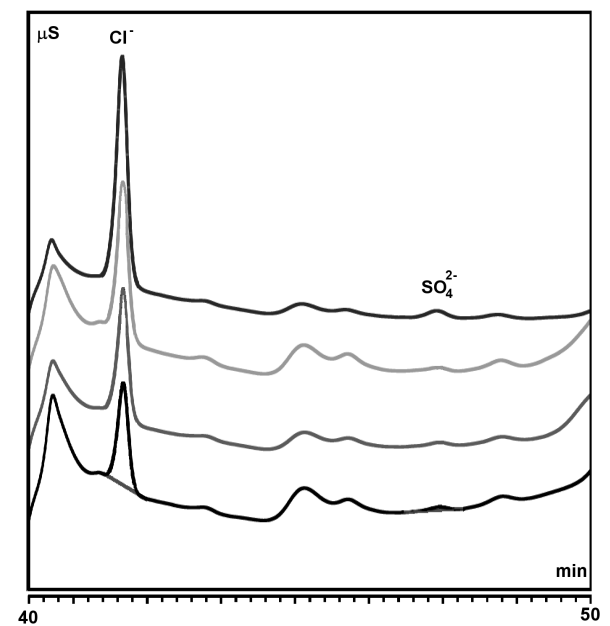

Figure S14. IC of vaporized Green E-liquid.

Bottom to top: replicates $1-3$ and the spiked sample. 


\section{REFERENCES}

(1) Slater, S. J.; Chaloupka, F. J.; Wakefield, M.; Johnston, L. D.; O'Malley, P. M. The impact of retail cigarette marketing practices on youth smoking uptake. Arch. Pediatr. Adolesc. Med. 2007, 161, 440-445.

(2) Bassett, R. A.; Osterhoudt, K.; Brabazon, T. Nicotine poisoning in an infant. N. Engl. J. Med. 2014, 370, 2249-2250.

(3) Measham, F.; O’Brien, K.; Turnbull, G. "Skittles \& Red Bull is my favourite flavour": E-cigarettes, smoking, vaping and the changing landscape of nicotine consumption amongst British teenagers-implications for the normalisation debate. Drugs 2016, 23, 224-237.

(4) Zhu, S. H.; Sun, J. Y.; Bonnevie, E.; Cummins, S. E.; Gamst, A.; Yin, L.; Lee, M. Four hundred and sixty brands of e-cigarettes and counting: implications for product regulation. Tob. Control 2014, 23 Suppl 3, iii 3-9.

(5) Kamboj, A.; Spiller, H. A.; Casavant, M. J.; Chounthirath, T.; Smith, G. A. Pediatric exposure to e-cigarettes, nicotine, and tobacco products in the united states. Pediatrics 2016, 137, e20160041.

(6) Talbot, P. Potential health effects of electronic cigarettes: a systematic review of case reports. Prev. Med. Rep. 2016, 4, 169-178.

(7) Jensen, R. P.; Strongin, R. M.; Peyton, D. H. Solvent chemistry in the electronic cigarette reaction vessel. Sci. Rep. 2017, 7, 42549.

(8) Tierney, P. A.; Karpinski, C. D.; Brown, J. E.; Luo, W.; Pankow, J. F. Flavour chemicals in electronic cigarette fluids. Tob. Control 2016, 25, e10-5.

(9) Spence, C.; Levitan, C. A.; Shankar, M. U.; Zampini, M. Does food color influence taste and flavor perception in humans? Chemosens. Percept. 2010, 3, 68-84.

(10) Burdock, G. A.; Carabin, I. G. Generally recognized as safe (GRAS): history and description. Toxicol. Lett. 2004, 150, 3-18.

(11) Thorngate, J. Synthetic Food Colorants. In Food additives; 2nd ed.; Branen, A. L., Ed.; Marcel Dekker, Inc.: New York, 2002, p 422-500.

(12) Code of Federal Regulations, Title 21, Parts 70, 73, 74, and 82 and Section 101.22(k). (2012) U.S. Government Printing Office; Available from:

http://www.fda.gov/ForIndustry/ColorAdditives/ColorAdditiveInventories/default.htm. (Accessed September 20, 2017).

(13) Nollet, L. M. L. Handbook of food analysis. Residues and other food component analysis.; Marcel Dekker: New York, 2004; Vol. 2.

(14) Petigara Harp, B.; Miranda-Bermudez, E.; Barrows, J. N. Determination of seven certified color additives in food products using liquid chromatography. J. Agric. Food Chem. 2013, 61, 3726.

(15) Recommended method No. 81: Routine analytical machine for e-cigarette aerosol generation and collection - definitions and standard conditions. CORESTA; Available from: https:/www.coresta.org/routine-analytical-machine-e-cigarette-aerosol-generation-andcollection-definitions-and-standard. (Accessed September 1, 2016).

(16) Fast HPLC analysis of dyes in foods and beverages, Dionex Corporation, 2010.

(17) Peiperl, M. D.; Prival, M. J.; Bell, S. J. Determination of combined benzidine in FD\&C Yellow No. 6 (Sunset Yellow FCF). Food Chem. Toxicol. 1995, 33, 829-839. 
(18) Lancaster, F. E.; Lawrence, J. F. Determination of benzidine in the food colours tartrazine and sunset yellow FCF, by reduction and derivatization followed by high-performance liquid chromatography. Food Addit. Contam. 1999, 16, 381-90.

(19) Lancaster, F. E.; Lawrence, J. F. Determination of total non-sulphonated aromatic amines in tartrazine, sunset yellow FCF and allura red by reduction and derivatization followed by high-performance liquid chromatography. Food Addit. Contam. 1991, 8, 249-263.

(20) Bailey Jr, J. E.; Bailey, C. J. Determination of aromatic amines in FD\&C Yellow No. 5 by diazotization and coupling followed by reversed-phase HPLC. Talanta 1985, 32, 875882.

(21) Robinson, G. Tartrazine - the story so far. Food Chem. Toxicol. 1988, 26, 73-76.

(22) Hurst, W. J.; Mckim, J. M.; Martin, R. A. Determination of tartrazine in foodproducts by hplc. J. Food Sci. 1981, 46, 419.

(23) Juhlin, L.; Michaelsson, G.; Zetterstrom, O. Urticaria and asthma induced by foodand-drug additives in patients with aspirin hypersensitivity. J. Allergy Clin. Immunol. 1972, 50, 92-98.

(24) Settipane, G. A.; Chafee, F. H.; Postman, I. M.; Levine, M. I.; Saker, J. H.; Barrick, R. H.; Nicholas, S. S.; Schwartz, H. J.; Honsinger, R. W.; Klein, D. E. Significance of tartrazine sensitivity in chronic urticaria of unknown etiology. J. Allergy Clin. Immunol. 1976, 57, 541546.

(25) Cheeseman, M. Certified color additives and childhood hyperactivity Office of Food Additive Safety. Food Advisory Committee; Available from:

https://www.fda.gov/downloads/AdvisoryCommittees/CommitteesMeetingMaterials/FoodAdvis oryCommittee/UCM273030.pdf. (Accessed September 20, 2017).

(26) Evaluation of certain food additives: eighty-second report of the Joint FA; FAO, World Health Organization: Expert Committee on Food Additives, 2016.

(27) Reineccius, G.; McGorrin, R. J. Source book of flavors In Trends in Food Science and Technology; 2 ed. 1994; Vol. 5, p 798.

(28) Chou, S. S.; Lin, Y. H.; Cheng, C. C.; Hwang, D. F. Determination of synthetic colors in soft drinks and confectioneries by micellar electrokinetic capillary chromatography. $J$. Food Sci. 2002, 67, 1314-1318.

(29) de Andrade, F. I.; Florindo Guedes, M. I.; Pinto Vieira, I. G.; Pereira Mendes, F. N.; Salmito Rodrigues, P. A.; Costa Maia, C. S.; Marques Avila, M. M.; de Matos Ribeiro, L. Determination of synthetic food dyes in commercial soft drinks by TLC and ion-pair HPLC. Food Chem. 2014, 157, 193-198.

(30) Yang, Y.; Zhang, J.; Shao, B. Quantitative analysis of fourteen synthetic dyes in jelly and gummy candy by ultra performance liquid chromatography. Anal. Meth. 2014, 6, 58725878.

(31) Hajimahmoodi, M.; Afsharimanesh, M.; Moghaddam, G.; Sadeghi, N.; Oveisi, M. R.; Jannat, B.; Pirhadi, E.; Zamani Mazdeh, F.; Kanan, H. Determination of eight synthetic dyes in foodstuffs by green liquid chromatography. Food Addit. Contam. Part A 2013, 30, 780-785.

(32) Fuh, M. R.; Chia, K. J. Determination of sulphonated azo dyes in food by ion-pair liquid chromatography with photodiode array and electrospray mass spectrometry detection. Talanta 2002, 56, 663-671.

(33) Feng, F.; Zhao, Y.; Yong, W.; Sun, L.; Jiang, G.; Chu, X. Highly sensitive and accurate screening of 40 dyes in soft drinks by liquid chromatography-electrospray tandem mass spectrometry. J. Chromatogr. B Analyt. Technol. Biomed. Life. Sci. 2011, 879, 1813-1818. 
(34) Alves, S. P.; Brum, D. M.; Branco de Andrade, E. C.; Pereira Netto, A. D. Determination of synthetic dyes in selected foodstuffs by high performance liquid chromatography with UV-DAD detection. Food Chem. 2008, 107, 489-496.

(35) Clydesdale, F. M. Color as a factor in food choice. Crit. Rev. Food Sci. Nutr. 1993, $33,83-101$.

(36) Johnson, J. L.; Dzendolet, E.; Clydesdale, F. M. Psychophysical relationship between sweetness and redness in strawberry-flavored drinks. J. Food Prot. 1983, 46, 21-25.

(37) Chequer, F. M.; Lizier, T. M.; de Felicio, R.; Zanoni, M. V.; Debonsi, H. M.; Lopes, N. P.; Marcos, R.; de Oliveira, D. P. Analyses of the genotoxic and mutagenic potential of the products formed after the biotransformation of the azo dye Disperse Red 1. Toxicol. In Vitro 2011, 25, 2054-2063.

(38) Makkonen, U.; Juntto, S. Field comparison of measurement methods for sulphur dioxide and aerosol sulphate. Atmos. Environ. 1997, 31, 983-990.

(39) Vlase, T.; Vlase, G.; Modra, D.; Doca, N. Thermal behaviour of some industrial and food dyes. J. Therm. Anal. Calorim. 2007, 88, 389-393.

(40) Rehorek, A.; Plum, A. Characterization of sulfonated azo dyes and aromatic amines by pyrolysis gas chromatography/mass spectrometry. Anal. Bioanal. Chem. 2007, 388, $1653-$ 1662.

(41) Duell, A. Peyton Lab. Portland State University. Department of Chemistry.

(42) Damodaran, S. Amino acids, peptides and proteins. In Fennema's Food Chemistry; 4th ed.; CRC Press: Boca Raton, FL, 2008; Vol. 4, p 217-329.

(43) Bannach, G.; Almeida, R. R.; Lacerda, L.; Schnitzler, E.; Ionashiro, M. Thermal stability and thermal decomposition of sucralose. Eclet. Quim. J. 2009, 34, 21-26.

(44) de Oliveira, D. N.; de Menezes, M.; Catharino, R. R. Thermal degradation of sucralose: a combination of analytical methods to determine stability and chlorinated byproducts. Sci. Rep. 2015, 5, 9598.

(45) Rahn, A.; Yaylayan, V. A. Thermal degradation of sucralose and its potential in generating chloropropanols in the presence of glycerol. Food Chem. 2010, 118, 56-61.

(46) Dong, S. J.; Wu, J. J.; Liu, G. R.; Zhang, B.; Zheng, M. H. Unintentionally produced dioxin-like polychlorinated biphenyls during cooking. Food Control 2011, 22, 1797-1802. 